\title{
ON AND OFF - LINE QUALITY CONTROL FOR PRODUCT DESIGN AND MANUFACTURING PROCESSES
}

\author{
Dr. Godfrey C. Onwubolu, C.Eng., CISE, CISP \\ Department of Industrial Engineering \\ National University of Science and Technology, Bulawayo, Zimbabwe
}

\begin{abstract}
The Taguchi methodology which may be applied as off-line quality control in the product design stage or, as on-line quality control during production is presented. As an off-line quality improvement strategy, it is a preventive measure at the product or manufacturing systems design stage which has the capability of making the product design robust. As an on-line quality improvement strategy, it assists in diagnosing the cause of the variation during production for the purpose of either eliminating the cause of variation or redesigning the product/process to make the product robust against the effect of the variation. The results of a case study presented using a computer program developed show that the Taguchi methodology can lead to substantial improvements.
\end{abstract}

\section{INTRODUCTION}

To deliver competitive products, manufacturers must change their strategy from solving quality problem ${ }^{5}$ by inspecting products to designing quality into products. World class manufacturing can be attained only by designing products and manufacturing processes to resolve problems before they occur during usage by customers. Poorly designed product puts responsibility on customers to incur losses from initial design stage through to when delivery is made.

The traditional way of considering quality in products and processes is shown in Figure 1 in which quality is only given attention during the actual production at the shop floor and during the receipt of incoming raw materials. Product delivered to customer merely passes some acceptance level, with no guarantee that it will meet customer requirements. There is no feedback to the designer who initiated the product, and manufacturing department merely uses statistical failure data to seek for possible causes. Operators in most cases are not often courageous to report defects noticed during production. The result is excessive loss to manufacturers and high price by customers because they are paying for losses incurred throughout the product development stream. More recently, quality culture has changed and manufacturers have realised that if they are to remain in business and compete effectively in the market place, they must begin to consider quality right from when the customer places order for a product to when the final product is delivered. Figure 2 shows this new trend.

Cost incurred during the design cycle affects the concept development, demonstration validation, fullscale development, production and operations support. It has been realised by manufacturers that about $70 \%$ of product development cost is incurred at the conception development stage, and changes made in later stages very close to production affect only about $30 \%$. Since changes made at the design stage do: not cost much as compared to high costs that are involved in attempting to make changes at the production stage due to detailed planning that has taken place, it is therefore useful to consider quality early enough at the design stage. 
Once the customer's voice has been captured using quality"deployment function, building quality into product has the effect of satisfying customer requirement at low price, and just in time.

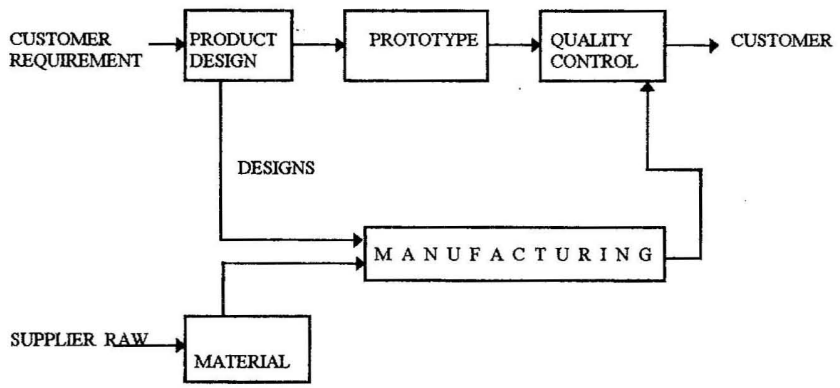

Figure 1 Traditional approach to quality in manufacturing

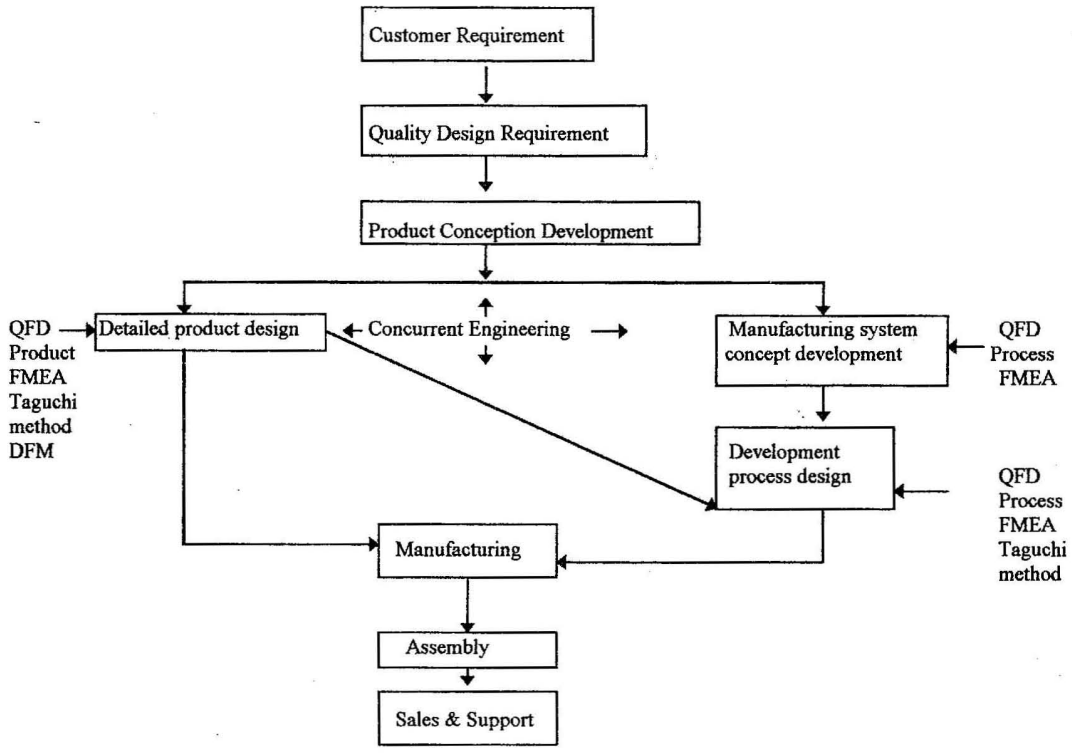

Figure 2 The new trend of considering quality early enough in design

This paper outlines the steps which are taken in order to design quality into products and manufacturing processes, and describes the role which computers play in accelerating the implementation. One computer software - QUALITY developed by the author is being used to study the Taguchi method for optimising product and process design and is used for all results published in this paper. The program covers the design, analysis and loss function discussed in this paper. Computerising such procedure enables manufacturers respond quickly to, and satisfy customer requirements. In the remaining part of this article, the term experiment refers to the procedure taken to optimise product and process design. 


\section{TAGUCHI METHODS FOR QUALITY CONTROL}

The contribution of Dr. Genichi Taguchi [1,2] to the field of quality engineering is one of the most significant in the last few decades. Taguchi method is currently one of the most acclaimed techniques for building quality into product. Following his contribution towards solving Japanese telephone system problems, he developed new methods which are totally different from traditional procedures for optimising engineering experimentation. These methods known as Taguchi methods have become invaluable tools for designing quality into products early enough in the product development. The fundamental concepts of Taguchi method are quite simple: 1) quality should be designed, and not inspected into the product 2) quality is best achieved by minimising deviation from functional target 3 ) quality cost should be measured as a function of the target and the losses incurred should be viewed as being systemic. These fundamental concepts have far reaching effects in manufacturing industries and many companies in Western countries have applied them in order to change their quality culture and solve quality problems which were almost, if not impossible to solve. Taguchi method answers these three questions: when do we start considering quality, how do we effect it, and what cost is involved ? The observations of Deming [3] that $85 \%$ of poor quality is attributed to the manufacturing process and only $15 \%$ to the worker was instrumental to Taguchi's development of robust manufacturing systems.

In the first concept, Taguchi states that quality improvement should be started at the design phase of a product or process and it should cascade into the production phase. Taguchi proposed an off-line strategy (as far as possible away from the production phase) of building quality improvement into the product rather than the traditional approach of inspection during production.

In the second concept, Taguchi views quality as directly related to deviation to a design parameter from a target value. By developing manufacturing processes to satisfy a specified target value, with little deviation, it is possible to improve the product life cycle. The second concept is concerned with how to effect quality.

In the third concept, designers are instructed to measure deviations from a given design parameter in relation to the overall life cycle cost of the product. Costs include rejects during production, warranty service call, replacement, etc. Tremendous cost improvements can be made at the design stage using Taguchi method, as we shall demonstrate later in this section.

Off-line quality improvement techniques take place away from the actual production point, normally at the product or manufacturing systems design stage. The Taguchi off-line quality improvement strategy is a preventive measure at the product or manufacturing systems design stage which has the capability of making the product design robust, hence becoming immune to external uncontrollable environmental noise factors such as humidity, ambient temperature, machinery deterioration, tool wear, and batch to batch variation operators. The strategy guarantees that the product delivered will meet customer requirements because the potential problems which might occur during usage have been considered early enough in the design stage. Quality improvement techniques at the point of production are termed on-line techniques. If quality is only considered down - stream very close to the point of manufacturing, much cost will be incurred in re - work, scraps, and customer warranty. Disney and Bendell [4] show the relationship between off-line and on-line quality controls (see Figure 3). Various sources of literature on Taguchi philosophies and methodologies include Addelman [5], Ishikawa [6], Juran [7], Lucas Engineering and Systems [8] and Ross [9]. For a full discussion on the use of Taguchi in on-line quality control see Taguchi [10].

The three stages in the design process to achieve off-line product quality recommended by Taguchi, are: systems design in which the overall factors affecting the system are determined, parameter design in which the factors affecting the performance of the product or process are specified, and tolerance design in which allowable range of deviation in the parameter values that affect the product are defined. The five steps to applying Taguchi method are: 1) define the problem; 2) experiment 
design; 3) conduct the experiment; 4) analysis of variance ; and 5) confirm the improvement by determining the loss function.

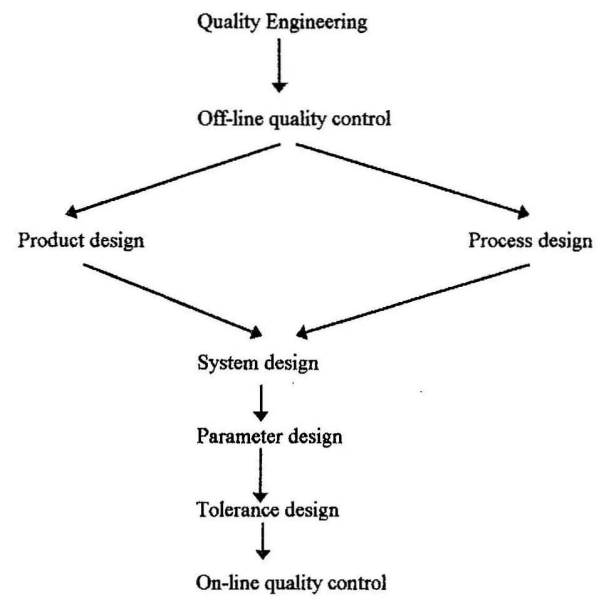

Figure 3. Stages of Quality Control

\subsection{QUALITY FACTORS}

Two types of factors are commonly used in Taguchi method: design or control factors, and noise or uncontrollable factors. For design factors, as much as possible, all factors which may affect the design have to be exhaustively considered, then prioritized in terms of their relative importance. The factors with higher weighting of importance are then filtered and used in the experiment. The number of levels have to decided too. In the planning stage it is important to decide what constitutes noise factors in the experiment, and what steps are to be taken to design a product that is insensitive to variations in these noise factors. Similarly, the number of factors and their levels have to be determined. Another important point to consider is the factors which are likely to interact; a decision has to be taken whether to include interactions among factors or replace them with additional factors.

\subsection{QUALITY DESIGN}

The traditional method of laying out the conditions or designs of experiments is to identify all possible combinations for a set of factors. These factors may be design factors (off-line) or manufacturing process factors (on-line). Known as factorial design of experiments, it has been used extensively by scientists since the $1920 \mathrm{~s}$ when it was first proposed by Fisher [11]. For example, an experiment that involves three factors at two levels, requires $8\left(2^{3}\right)$ combinations; and in general, an experiment that involves $\mathrm{n}$ - factors at $\mathrm{m}$ - levels, requires $\mathrm{m}^{\mathrm{n}}$ combinations. A factorial experiment of 3 factors, at 2 levels each, is shown in Figure 6.4 (a) with all the 8 combinations. We represent the factors as A, B, and $C . A_{1}, B_{1}$, and $C_{1}$ represent the values of the factors at level 1 , while $A_{2}, B_{2}$, and $C_{2}$ represent the values of the factors at level 2 .

A special set of orthogonal arrays (OAs) were devised by Taguchi for designing an experiment. The cells in Figure 4(a) marked with asterisk represent the Taguchi partial factorial orthogonal array for the experiment. The Taguchi orthogonal array reduces the number of factors to be considered, to 4 instead of 8 in the factorial method. Figure 4 (b) shows the Taguchi orthogonal array, in which factors affecting a design are assigned to the top row, while trial numbers are placed on the first column. The 
relationship between the design factors and trial numbers is described by the trial conditions with factor levels indicated by integer numbers. The Taguchi experimental technique is useful in a wide range of situations where solutions are not straight forward, as in the case where there are multi-reasons for defect or deficiency.

\begin{tabular}{|l|l|l|l|}
\hline & & $\mathrm{A}_{1}$ & $\mathrm{~A}_{2}$ \\
\hline \multirow{3}{*}{$\mathrm{B} 1$} & $\mathrm{C}_{1}$ & $*$ & \\
\hline & $\mathrm{C}_{2}$ & & $*$ \\
\hline \multirow{3}{*}{$\mathrm{B} 2$} & $\mathrm{C}_{1}$ & & $*$ \\
\cline { 2 - 4 } & $\mathrm{C}_{2}$ & $*$ & \\
\hline
\end{tabular}

\begin{tabular}{|l|l|l|l|}
\hline \multicolumn{4}{|c|}{ Factors } \\
\hline \multicolumn{1}{|c|}{ Trials } & 1 & 2 \\
\hline 1 & 1 & 1 & 1 \\
2 & 1 & 2 & 2 \\
3 & 2 & 1 & 2 \\
4 & 2 & 2 & 1 \\
\hline
\end{tabular}

Figure 4 Taguchi design experiment using L4 (2/3) array

\section{Control and noise orthogonal arrays}

In control orthogonal arrays, the control parameters are assigned to the columns of the orthogonal array, and the integers are translated into actual tests values of the assigned parameters. The control orthogonal array is known as inner array. The noise array is known as outer array and it is used to introduce real life factors which are not under the control of the engineer. For example, the engineer cannot directly control the humidity under which the product or process design will operate. Therefore humidity is considered to be noise variable. The normal method in Taguchi experiment is to carry out the experiment using the control factors, under different conditions of a noise variable such as humidity. These uncontrollable factors as they are called are also treated like the control factors using orthogonal arrays. However, noise (outer) array is placed perpendicular to control (inner) array as shown in Figure 5. In practice, the outer array describes the noise conditions for the repetitions.

\begin{tabular}{|c|c|c|c|c|c|c|}
\hline & & & $\begin{array}{l}\mathrm{N} \\
\vec{\Phi} \\
\vec{J}\end{array}$ & $\begin{array}{l}\bar{w} \\
\tilde{n}^{2} \\
8 \\
\bar{n}\end{array}$ & 总 & \begin{tabular}{l}
$x$ \\
\multirow{2}{n}{}
\end{tabular} \\
\hline & & rray & एँ & $\begin{array}{l}\bar{n} \\
2 \\
0 \\
n \\
n\end{array}$ & $\begin{array}{l}8 \\
8 \\
8\end{array}$ & ㅁ. \\
\hline Inner Array & & & 总 & 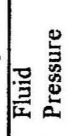 & 몰 & 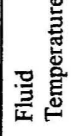 \\
\hline Control Factors & & & Rep & itition & Res & $(t s)$ \\
\hline Column & 1 & 2 & 3 & 1 & 2 & 3 \\
\hline 1 & 1 & 1 & 1 & 40 & 45 & 38 \\
\hline 2 & 1 & 2 & 2 & 30 & 35 & 32 \\
\hline 3 & 2 & 1 & 2 & 45 & 48 & 40 \\
\hline 4 & 2 & 2 & 1 & 35 & 40 & 36 \\
\hline
\end{tabular}

Figure 5. Inner and outer orthogonal arrays describing control and noise factors 


\section{Designing with interactions}

There are cases in practice when the effect of changes in the level of a factor determines the influence of another factor, and vice versa. When this happens, the two factors are said to interact. The commonest example which most people can easily relate to, is the effect of temperature and humidity on human comfort. Lowering temperature alone causes some degree of discomfort but this is heightened by lowering humidity in addition. Temperature and humidity have interaction on each other, when considering human comfort.

Designing using interactions needs special attention. Not all orthogonal arrays accommodate interaction. Typically, arrays which accommodate interactions are those which can be described as $2^{k+1}$ - type $\left(L_{4}, L_{8}, L_{16}, L_{32}\right.$ etc. for level 2), $3^{k+1}$ - type $\left(L_{9}, L_{27}, L_{81}\right.$, etc. for level 3), ..., $m^{k+1}$ type where $k=1,2, \ldots, n$. Figures 6 (a) - (d) show linear graphs for $L_{4}, L_{8}, L_{16}$, and $L_{32}$. The nodes represent control parameters, while the line segments represent interactions. The effect of interaction is usually reserved for control parameters while repetitions are considered for noise parameters. There are several methods of constructing linear graphs but one which is easy to understand using level 2 orthogonal arrays as example, is described in the following steps.

* Step 1. Assign node 1, then connect a line segment to node 2.

* Step 2. Continuing other $\mathrm{m}$ - line segments to obtain other nodes, where $2^{\mathrm{m}}$ corresponds to $\mathrm{L}_{2} \mathrm{~m}$.

* Step 3. Connect all nodes

For example in constructing an $\mathrm{L}_{16}$ array, we assign node 1 , connect line segment to node 2 . There are remaining 4 - segments to form a polygon since $2^{4}=16$. Therefore in the design, the control parameters are assigned to nodes $1,2,4,8$, and 15 . It is observed that intermediate nodes between nodes 1 and the last nodes are multiples of 2 . All nodes are then connected as shown in Figure 6 (c), with line segments designated $3,5,6,7,9,10,11,12,13$ and 14 . The interaction between columns 1 and 2 is column 3 , between columns 2 and 4 is column 6 , etc.

There are rules for assigning columns of the orthogonal array when interactions exist. Using the linear graphs, the control parameters are assigned to the orthogonal array columns corresponding to the nodes of the linear graph. When nodes are used up, the line segments are assigned. The columns for interaction should be filled according to the labels in the linear graph.

3
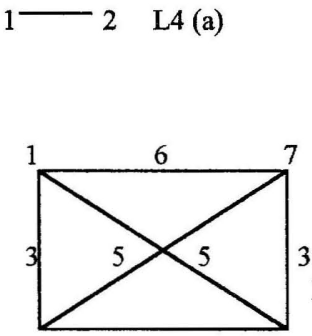

2

6

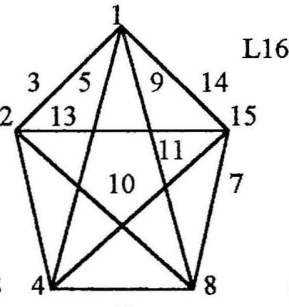

12

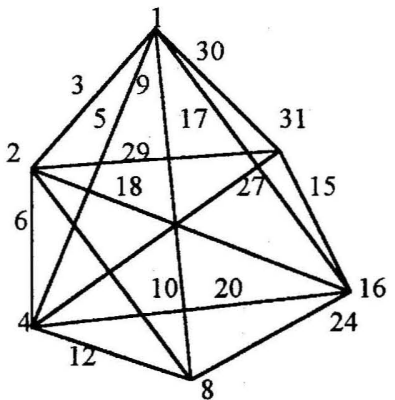

(d) $\mathrm{L} 32$ 

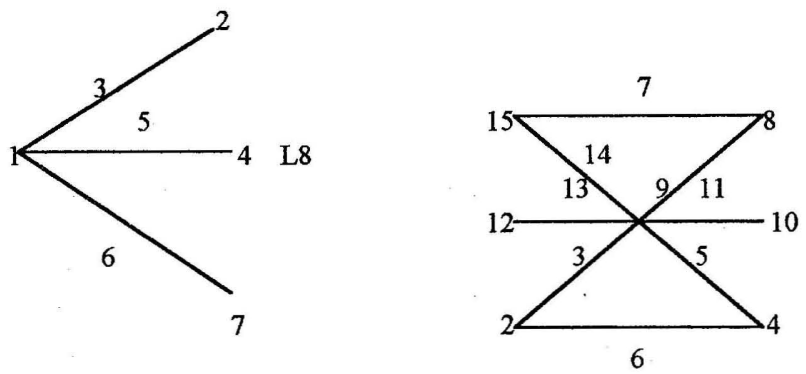

Figure 6 Linear graphs showing interactions

\section{Upgrading and collapsing levels in mixed factors design}

Mixed factors exist in practical design for optimisation of products and processes. The details of this technique is not discussed in this paper.

\subsection{QUALITY ANALYSIS}

A methodical way of analysing the Taguchi design is the use of analysis of variance techniques (ANOVA) in statistics. ANOVA easily indicates which design factors are important so that we concentrate on their effects and by so doing, we filter the less important factors. The basic computations which are covered in ANOVA are as follows:

* Degrees of freedom (f)

* Sum of squares (s)

* Mean square (variance) (V)

* Variance ratio (F)

* Pure sum of squares ( $\left.\mathrm{S}^{\prime}\right)$

* Percentage contribution (p)

Repetition of the experiments for several number of times is normally recommended. But when only one set of experimental readings are taken, only one column is utilised. This simple procedure for design applies to any complicated problem, once the necessary factors have been determined.

The solution of optimum performance may be obtained from the ANOVA result by considering pooling effect. Pooling means adding the effect of factors that are not very significant to other significant factors. The optimum performance value gives indication of the signal to noise ratio $(\mathrm{S} / \mathrm{N})$ which is an input to the Taguchi loss function (TLF).

\subsection{QUALITY COST}

Two kinds of losses are taken seriously. The first, is loss incurred by manufacturers from their supplier, and the second and more important is the loss incurred by customers when they purchase products which have poor quality. Taguchi aims at minimising losses throughout the product development stream so that customers at the front end do not have to incur unnecessary costs which are measured in monetary terms. Taguchi defined a loss function which is proportional to the deviation from the target quality characteristic, given in parabolic form as shown in Figure 7. 


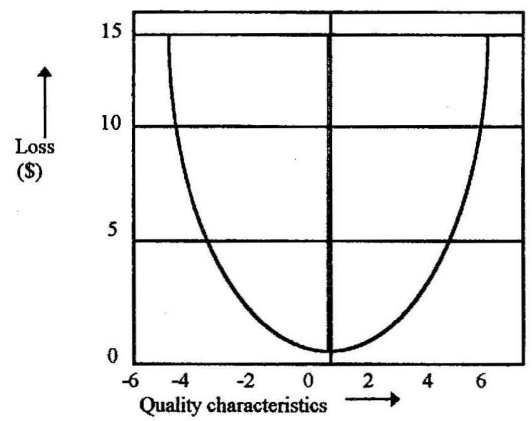

Figure 7 Taguchi loss function

\section{CASE STUDY}

A contracting firm involved in making automobile body parts for major motor industries is concerned with the cost incurred in re-work of parts. The firm uses mainly mechanical presses for piercing operations for sheet-metal work. Progressive die is used for producing the parts, with flat sheet-metal being progressively released from the stock reel, and it passes through the air feeder for straightening and finally through the die where the press pierces out the required part shape. As the sheet-metal passes through the air feeder, it is cooled using a coolant. There is also a sag between the stock reel and the air feeder.

A Taguchi experiment was carried out to: identify the cause of the variation of the manufactured parts from the target; use the knowledge of the cause of variation to either eliminate the cause of variation or redesign the product/process in order to make the product robust against the effects of the variation.

In order to proceed with the task, the factors which affected production were first identified as: the stock reel speed, press punch speed, angle of deflection of the sheet-metal, the feeder release rate, lubricant flow rate. These factors are designated A, B, C, D, E. It is found that two interactions exist: between $\mathrm{A}$ and $\mathrm{C}$, and between $\mathrm{B}$ and $\mathrm{C}$. Management therefore considers that there are seven factors which are considered to have significant impact on the quality of product and that they are two levels for each factor, hence an L8 (2/7) Taguchi orthogonal array is needed to investigate the factors A, B, C, $\mathrm{D}, \mathrm{E}$ which are assumed to be causing high production scraps. The operations manager of the company receives results of scraps taken at a machine centre by an operator at the interval of 2 hours (see Table 1a). There are 8 readings shown in Table $1 \mathrm{~b}$, representing the averages of readings taken at the specified times. We use Taguchi method for investigating this problem, and carry out a complete analysis of variance (ANOVA) for the problem. The monthly saving derived from the experiment is also to be computed, based on the following information:

Target value $=40$

Tolerance $=2$

Reject cost per unit $=\$ 1.00$

Production rate per month $=10000$ 
Table 1a. Design factors and their levels

\begin{tabular}{|llll|}
\hline Column & Factors & Level 1 & Level 2 \\
\hline 1(A) & Reel speed & Low & High \\
2(C) & Reel angle & Small & Large \\
3(AxC) & & & \\
4(B) & Press speed & Low & High \\
5(D) & Air feeder release & Slow & Fast \\
6(BxC) & & & \\
$7(\mathrm{E})$ & Lubricant flow rate & Low & High \\
\hline
\end{tabular}

Table 1b. Taguchi experiment data with interactions included

\begin{tabular}{|lllllllll|}
\hline & A & C & AxC & B & D & BxC & E & RESULTS \\
\hline & 1 & 2 & 3 & 4 & 5 & 6 & 7 & (y) \\
\hline 1 & 1 & 1 & 1 & 1 & 1 & 1 & 1 & 50 \\
2 & 1 & 1 & 1 & 2 & 2 & 2 & 2 & 55 \\
3 & 1 & 2 & 2 & 1 & 1 & 2 & 2 & 45 \\
4 & 1 & 2 & 2 & 2 & 2 & 1 & 1 & 52 \\
5 & 2 & 1 & 2 & 1 & 2 & 1 & 2 & 60 \\
6 & 2 & 1 & 2 & 2 & 1 & 2 & 1 & 42 \\
7 & 2 & 2 & 1 & 1 & 2 & 2 & 1 & 58 \\
8 & 2 & 2 & 1 & 2 & 1 & 1 & 2 & 48 \\
\hline
\end{tabular}

\section{Quality factors}

The design factors are $\mathrm{A}, \mathrm{C}, \mathrm{AxC}, \mathrm{B}, \mathrm{D}, \mathrm{BxC}$, and $\mathrm{E}$ given in the problem formulation.

Quality design

The Taguchi orthogonal array of Table $1 \mathrm{~b}$ shows the design. The linear graph of Figure $5(\mathrm{~b})$ shows that interaction between nodes 1 and 2 is at line segment 3 , while that between nodes 2 and 4 is at line segment 6 . These information are used to assign the factors at the top of Table $1 \mathbf{b}$.

Quality analysis:

The results in Tables 2 and 3 constitute the quality analysis results which were using the software QUALITY. Estimate of the Optimum Condition of Design / Manufacturing Process based on 'smaller the better characteristic' is shown in Table 3. 
Table 2 ANOVA results

\begin{tabular}{|cllllll|}
\hline Source f & S & V & F & S & P \\
\hline A & 1 & 4.5 & 4.5 & 0 & 0 & 1.645338 \\
C & 1 & 2 & 2 & 0 & 0 & 0.7312614 \\
AxC & 1 & 18 & 18 & 0 & 0 & 6.581353 \\
B & 1 & 32 & 32 & 0 & 0 & 11.70018 \\
D & 1 & 200 & 200 & 0 & 0 & 73.12614 \\
BxC & 1 & 12.5 & 12.5 & 0 & 0 & 4.570384 \\
E & 1 & 4.5 & 4.5 & 0 & 0 & 1.645338 \\
Error & 0 & 0 & 0 & 0 & 0 & 0 \\
(before pooling) & & & & & \\
\hline Totals 7 & & & & & & \\
\hline
\end{tabular}

Table 3 Optimum solution

\begin{tabular}{|ll|}
\hline Factor description & Contribution \\
\hline Contribution from all factors (total) & -9.75 \\
Current grand average of & \\
performance & 51.25 \\
Optimum result & 41.50 \\
\hline
\end{tabular}

The result shows 4 significant factors - $\mathrm{AxC}(6.6 \%), \mathrm{B}(11.7 \%), \mathrm{D}(73 \%), \mathrm{BxC}(4.5 \%)$. The pooled factors are $\mathrm{A}(1.6 \%), \mathrm{B}(0.7 \%), \mathrm{E}(1.6 \%)$. Hence the firm is informed that the most important factor is $\mathrm{D}$ with as much as $73 \%$ of the overall effect. The firm is informed not to too concerned with the effects of A, C, and E, and so spends more time and on the important factors. Non-value activities are greatly reduced and important factors which affect the quality of the product or process are highlighted. Upper and lower bounds are determined by the analysis as 42 and 61 respectively, beyond which management cannot tolerate scraps.

\section{Quality cost}

Taguchi loss function is the deviation from the target quality characteristic. It is an excellent tool for determining the magnitude of the process and supplier tolerances, based upon quality as perceived by the customer. By determining the loss before and after the Taguchi experiments, it is possible to estimate the savings to the firm. The following results were obtained for the press investigation:

Loss before experiment $=\$ 40.18$

Loss after experiment $=\$ 32.64$

Monthly savings:

Based on production rate of $10000 /$ month $=\$ 75400$ 


\section{CONCLUSION}

We considered Taguchi method in detail because it is one of the most powerful tools available to the designer for building quality into the product and diagnosing the cause of variation during production for the purpose of either eliminating the cause of variation or redesigning the product/process to make the product robust in order to satisfy customer requirement. Operations managers and engineers should rigorously seek for methods which are capable of solving problems in products and processes before they occur.

\section{REFERENCES}

[1] Taguchi, G., 1987, "System of Experimental Design", New York: UNIPUB, Kraus International Publications.

[2] Taguchi, G. and Konishi, S., 1987, "Orthogonal Arrays and Linear Graph - Tools for Quality Engineering", Dearborn, Michigan: American Supplier Institute, Inc.

[3] Deming, W. E., 1986, "Out of Crisis", Cambridge, M A: Massachusetts Institute of technology, Centre for Advanced Engineering Study.

[4] Disney, J. and Bendell, A., 1990, "The Potential for the Application of Taguchi Method of Quality Control in British Industry", In Managing Quality, (Eds: Dale, B. G. and Plunkett, J. J.), Philip Allan Publishers.

[5] Addelman, S., 1962, "Orthogonal main-effect plans for asymmetrical factorial experiments", Technometrics, No. 4, Vol. 1, pp. 21-46.

[6] Ishikawa, K, 1985, "What is Total Quality Control? The Japanese Way", Englewood Cliffs, N J: Prentice-Hall, Inc.

[7] Juran, J. M., Gryna, F. M., Jr., and Bingham, R. S., Jr., 1979, "Quality Control Handbook", 3rd ed. New York: MacGraw-Hill.

[8] Lucas Engineering and Systems, 1992, "The Lucas Manufacturing Systems Handbook: Mini Guides", Lucas Engineering and Systems Ltd.

[9] Ross, P. J., 1988, "Taguchi Techniques for Quality Engineering", McGraw Hill Book Co., New York.

[10] Taguchi, G., 1981, On-line Quality Control During Production, Japanes Standard Association. [11] Fisher, R. A., 1951, "Design of Experiments", Edinburgh: Oliver \& Boyd. 